\title{
Improving the Efficiency of the Remanufacture of Complex Mechanical Assemblies with Robust Inspection of Core Units
}

\author{
Sara J. Ridley \& W. L. Ijomah \\ Caterpillar Remanufacturing Services, Sanders Lodge Industrial Estate, Rushden, \\ Northamptonshire, NN10 6AZ. \\ ridley_sara_j@cat.com
}

\begin{abstract}
This paper presents the findings of experimental research carried out at a Caterpillar Remanufacturing facility in the UK into core inspection at the initial stage of remanufacture Receive Core. The initial analysis of results shows an increase in productivity with increase of inspection but that this increase is finite and over-inspection leads to an overall decrease of productivity and an increase in costs. However the results also show that the amount of viable inspection can be more closely linked to the cost of the component rather than the facility operating costs. This is important because remanufacturers traditionally base their pricing and product recovery on their operating costs. The new knowledge concerning the factors affecting the efficacy of core inspection is being used to develop a generic decision-making methodology for core inspection at component level to improve the overall efficiency (in terms of increased productivity and cost reduction) of the remanufacturing operation.
\end{abstract}

\section{Introduction}

Remanufacture, a process to return used product to an "as-new" condition with an equal warranty is typically carried out on complex mechanical assemblies as the remaining value in the used product is high. Remanufacturing is often a more efficient reuse strategy than recycling as, in addition to the reduction in landfill and the use of virgin material, it also reduces the amount of energy used in production by removing the need for raw material production and the subsequent shaping and machining processes thus slowing or reducing the production of greenhouse gas emissions such as $\mathrm{CO}_{2}$. Lund [1] suggested that up to $85 \%$ by weight of a remanufactured product may come from reclaimed components, and that remanufactured components have a comparable quality to new whilst requiring between $50 \%$ and $80 \%$ less energy to produce. This, as a whole, can produce manufacturing savings of between $20 \%$ and $80 \%$. Decreasing either work content or the included quantity of new material is the main route for remanufacturers to increase profitability.

There remain barriers to remanufacturing particularly around the paucity of research into the field. The development of a robust definition has helped to clarify the confusion with repair and reconditioning, however Guide [2] identified that remanufacturers perceive the scarcity of effective remanufacturing tools and techniques as a key threat to the industry. Ijomah [3] quantified these key characteristics on a five-point scale ranging from "Not Significant through to "Critical". The characteristic deemed to be most important to remanufacturers was component inspection - the only one rated as critical. Personal industrial experience and observation of the remanufacturing process has shown that this remanufacturing sub-activity, although it can have significant bearing on overall productivity, is often undertaken in a haphazard manner based almost purely on experience and guesswork and lacks proper methodologies and tools. However, it is known that efficiency and effectiveness are key requirements for enhancing profitability and productivity in a business environment. 


\section{Research Background}

It is usual practice in remanufacturing to inspect at all stages through the process, often functionally and in all cases visually. The result of this is a high quality product for customers but lowered profitability for the remanufacturer through either too little initial inspection leading to unnecessary processing and further inspection later through the process or through core being unnecessarily rejected early in the process and leading to a poor recovery rate. An in-depth literature survey undertaken as part of this research has proven that little research has been undertaken in the "Receive Core" remanufacturing sub-activity. This research will identify new knowledge about the factors that affect the inspection process and consequently provide a quantifiable approach to inspection at the critical "Receive Core" sub-activity potentially leading to improvements in the productivity of remanufacturing both at that stage and further through the process. This new knowledge is also intended to be accessible to operational managers as much of the research found during the literature review involved complex mathematics and, as discovered during preliminary interviews, is rarely adopted by industry. The automotive industry was selected because of its long history of remanufacturing.

Lund [1] defined three basic types of remanufacturer:

- OEM remanufacturers - often a process alongside their manufacturing operations;

- Third-party remanufacturers - remanufacturing under licence for the OEM and often, but not always with their technical support; and

- Independent remanufacturers - remanufacturing other people's goods without licence or support for direct sales into the aftermarket.

The key difference between independent remanufacturers and OEM and contract remanufacturers in terms of core is that in almost all cases the customers are responsible for return of core units with the remanufacturer having little control over the quantity, mix or quality of returns. This can have a significant impact on ability to supply customers particularly where the mix of core units cannot be guaranteed to match the mix of remanufactured units required by the customer. In addition, contract remanufacturers operate with fixed cost contracts that allow for no additional charge to be made for badly damaged or incorrect core.

This research builds on the research of Errington [4] who looked at core and inspection strategy in independent remanufacturers. The key difference here is that this research will augment that work by looking at both OEM and contract remanufacturing processes to identify the specific component characteristics that determine the appropriate level of inspection.

Caterpillar Remanufacturing Services is both an OEM remanufacturer and contract remanufacturer for a variety of automotive and industrial customers with four facilities across Europe. The facility at Rushden, where this research is being conducted, is primarily focused on remanufacturing petrol and diesel internal combustion engines with a capacity up to approximately 6 litres and their ancillary components (starter motors, fuel injection equipment, turbochargers etc.). Initial interviews with key staff at the facility suggested that the majority felt that any process other than a cursory inspection was a waste of time. 


\section{Experimental Method}

The aim of the experiment was to establish whether inspection of core made a material difference to the speed of remanufacture and hence productivity. An increase in productivity is defined and quantified, in this instance, as the additional units able to be processed because of a decrease in processing times and in-process scrap. In-process scrap figures were recorded for each of the major components (crankshaft, camshaft, cylinder head, cylinder block, conrods and, where applicable, starter motors, alternators, turbochargers and fuel injection equipment). Engines of varying types were inspected against differing criteria to measure what the effect of inspection was on the remanufacturing process.

Four engine types were selected to ensure a representative sample of engine types, sizes, applications, supplied dress level and customers. They were:

Engine A: Four cylinder, automotive petrol engine, supplied at long engine level*. Engine B: Six cylinder, automotive diesel engine, supplied at long engine level*. Engine C: $\quad$ Four cylinder, specialist application diesel engine supplied at full dress level**.

Engine D: $\quad$ Six cylinder, industrial application diesel engine supplied at full dress level**.

* Long engine level: Cylinder block, crankshaft, con-rods, camshafts and head, sump and covers, oil pump and water pump.

** Full dress level: Long engine level plus starter motor, alternator, compressor, fuel injection equipment, flywheel and turbocharger as applicable.

Four inspection protocols were developed to test the effect of different levels of inspection on the whole remanufacturing process. The extent of the inspection was limited by the available technology.

Protocol 1 - no inspection, decant, establish part number and reuse. This protocol was to test whether inspection of core made any material difference.

Protocol 2 - decant, establish part number, visual, external inspection and grading; either use, close to new - bypass the usual process or severely damaged - use as a parts donor. This is the usual process and acted as the baseline.

Protocol 3 - Protocol 2 plus manual rotation of moving parts, visual and scent inspection of rotating electrics and close inspection of open ports and oilways.

Protocol 4 - Protocol 3 plus inspection using a fibre optic endoscope to investigate the internal condition of cylinder bores, turbochargers, alternators etc.

Written standard work was provided for each inspection protocol, as were quality acceptance standards for decision-making.

Used core arrives at the facility from the OE manufacturer or their appointed core collector on a frequent but not regular basis and is often batched under a generic part number or type. As a consequence of this, core was essentially randomised at receipt. However, to ensure no inadvertent bias a protocol was assigned, $1-4$ in turn, to each core prior to decanting. Processing times for each stage of remanufacture as well as any in-process scrap was 
recorded. Each engine through the remanufacturing facility is assigned a unique tracking number and this was used to ensure all measured times were correctly recorded. Core units of all four selected types were measured over a period of 5 months with a total of 2196 engines studied.

\section{Preliminary Results}

It was anticipated from literature [5, 6,7,8 etc.] that there would be a productivity benefit from increased inspection but that this would lessen as inspection content increased. This was seen in engines $\mathrm{C}$ and $\mathrm{D}$ but the effect was less obvious on engines $\mathrm{A}$ and $\mathrm{B}$ (see figure 1).

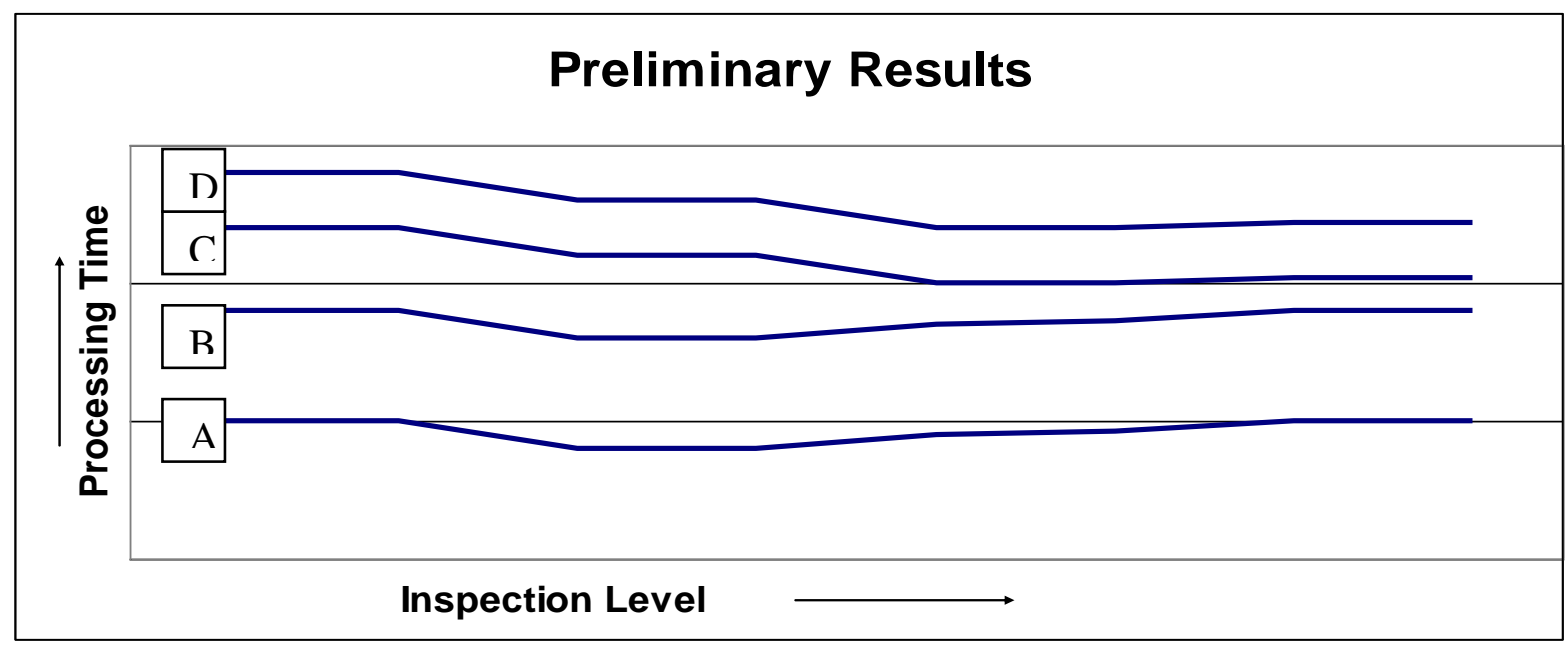

\section{Figure 1: Preliminary Results}

Table 1 (below) shows the average results for each engine and protocol. These summary results are shown here for clarity as the complete data comprised over 43,000 individual entries.

The in-process scrap figures were used to calculate the time spent processing components that were later disposed of and this time added to the processing time for each engine. The difference (positive or negative) between the baseline and each protocol time together with the available processing time in the factory (calculated from the standard working week and the operators dedicated to that particular engine) was then used to calculate the increase or reduction in weekly capacity arising from the individual protocol.

Initially the following was observed from the results:

- No inspection (Protocol 1) increased the overall processing time for all engines, with the majority of this increase being experienced in the disassembly phase;

- Engines supplied to the customer at long engine level showed little or no benefit from increased inspection;

- Protocols 3 and 4 produced a decrease in overall processing times for engines $\mathrm{C}$ and D;

- Protocol 3 produced the greatest decrease in overall processing times for engines $\mathrm{C}$ and D; 
- Increasing the level of inspection generally decreased the amount of in-process scrap; and

- Individual complex components (turbochargers, starter motors etc.) showed a greater decrease in both in-process scrap and processing time as the level of inspection increased.

\begin{tabular}{|c|c|c|c|c|}
\hline Engine & Protocol & $\begin{array}{c}\text { Processing time } \\
\text { (mins) }\end{array}$ & In-process scrap & $\begin{array}{l}\text { Additional } \\
\text { Capacity }\end{array}$ \\
\hline A & 1 & 580.53 & $12.20 \%$ & -0.81 units/week \\
\hline A & 2 & 568.69 & $10.16 \%$ & Baseline \\
\hline A & 3 & 571.78 & $9.78 \%$ & +0.03 units/week \\
\hline A & 4 & 584.79 & $9.67 \%$ & +0.47 units/week \\
\hline B & 1 & 892.75 & $13.86 \%$ & -0.89 units/week \\
\hline B & 2 & 863.59 & $10.18 \%$ & Baseline \\
\hline B & 3 & 870.76 & $10.02 \%$ & +0.13 units/week \\
\hline B & 4 & 898.00 & $10.11 \%$ & +0.50 units/week \\
\hline C & 1 & 1789.45 & $14.24 \%$ & -3.75 units/week \\
\hline C & 2 & 1738.61 & $11.71 \%$ & Baseline \\
\hline C & 3 & 1603.08 & $8.67 \%$ & +10.58 units/week \\
\hline C & 4 & 1631.64 & $8.59 \%$ & +8.71 units/week \\
\hline D & 1 & 2138.23 & $9.81 \%$ & -6.64 units/week \\
\hline D & 2 & 2124.94 & $8.42 \%$ & Baseline \\
\hline D & 3 & 1924.15 & $8.04 \%$ & +10.37 units/week \\
\hline D & 4 & 1943.21 & $7.94 \%$ & +9.29 units/week \\
\hline
\end{tabular}

$\underline{\text { Table } 1 \text { Average Results for Each Engine/Protocol }}$

Further examination showed that the largest impact on processing time, other than for disassembly, was seen in the ancillary components - turbochargers, starter motors, alternators etc. Preliminary examination of this indicates a two-fold benefit: firstly in earlier identification of required replacement parts and secondly in reduced processing times. Table 2 (below) illustrates this showing the improvement in processing times for the turbocharger of engine D.

\begin{tabular}{|l|c|c|c|}
\hline $\begin{array}{l}\text { Turbocharger } \\
\text { (D) }\end{array}$ & $\begin{array}{c}\text { Processing } \\
\text { time (mins) }\end{array}$ & $\begin{array}{l}\text { In-process } \\
\text { scrap }\end{array}$ & $\begin{array}{l}\text { Additional } \\
\text { Capacity }\end{array}$ \\
\hline Protocol 1 & 185.98 & $16.13 \%$ & -0.97 units/week \\
\hline Protocol 2 & 167.55 & $14.58 \%$ & Baseline \\
\hline Protocol 3 & 147.44 & $11.82 \%$ & +1.2 units/week \\
\hline Protocol 4 & 142.42 & $11.07 \%$ & +1.51 units/week \\
\hline
\end{tabular}

$\underline{\text { Table } 2 \text { Average Results for Engine D Turbocharger for each Protocol }}$ 


\section{Discussion}

Protocol 1 (no inspection) impacted clearly on the overall processing times. This was expected both from the local knowledge within the subject facility (Protocol 2 being the default inspection protocol) and from literature. The simple act of visually sorting core (Protocol 2) to ensure that pieces in the worst condition are either de-prioritised or used only as donors for replacement parts at need, ensures that time is not needlessly wasted disassembling parts that will be scrapped very quickly in the process. There was also an increase in in-process scrap that can be largely attributed to defect parts not being identified earlier in the process. This also was reduced by implementing protocol 2.

Protocols 3 and 4 showed a benefit by reducing processing times although this did not outweigh the additional inspection time where the engine dress level was limited to long engine (engines A and B), particularly for protocol 4. Individual process results link this to the lack of ancillary items supplied as part of the dress for long engine. Examination of the individual results strongly indicate that for simple components such as cylinder blocks, crankshafts, connecting rods, sumps etc. increasing the level of inspection past a visual inspection at the receive core stage gives little or no benefit in terms of reducing the overall processing times. There is a small benefit in terms of reducing in-process scrap but this is also outweighed by the increased inspection time.

Components that are more complex, in terms of the number, function and type of constituent parts, such as cylinder heads, have their processing times reduced when the level of inspection is increased. The information gained from the increase in inspection enables targeted remanufacturing operations - eliminating unnecessary steps and a more timely purchase of replacement parts.

The largest processing reduction can be seen in complex components. Those with the largest diversity of constituent parts (number, function and type, a starter motor typically has mechanical, electrical and electronic components) demonstrate the largest reduction in processing times as the variation in potential operations required to remanufacture the assembly is the widest.

The results indicate that inspecting component parts of a complex assembly to different levels would reduce overall processing times.

\section{Conclusions}

Inspection of core prior to use produces a benefit in terms of reducing the overall processing time. Experimental results show an increase in productivity from increased inspection. However, for relatively simple components that benefit is finite whereas the benefits increase dramatically as the complexity of the component increases. This has cost implications for remanufacturers. Typically a turbocharger, starter motor or other such part constitutes a large proportion of the value of an engine. Treating these components to a level of inspection greater than that typically given to the whole engine, brings a greater benefit. If the level of inspection considered viable for those components is judged as being proportional to their value in the overall engine rather than the typical current model of total time taken against the cost of the process, more inspection time can be justified, particularly if less time is allocated to simpler component parts. The increase in productivity, resulting in part from a decrease in in-process scrap as well as the lower processing time, and the cost benefits accrued from the 
reduction in processing time mean that the overall process efficiency is improved with greater inspection. This reduction in cost and according increase in efficiency remains to be quantified.

A methodology to assess the complexity of components and assemblies either by themselves or as part of a larger assembly and assign an appropriate inspection protocol is being developed to ensure the benefits observed during the experimental phase can be leveraged.

\section{Current Work}

A further set of engines of types $\mathrm{C}$ and $\mathrm{D}$ are being observed through the remanufacturing process in order to validate the experimental findings by separating ancillary components and inspecting them to protocol 4 . Half of this set of engines has had the remainder of the engine inspected to protocol 2 and the other half to protocol 3. The component parts are in process and times are being measured for all stages of the remanufacture.

The results of this further experiment will be used to inform the inspection methodology. In addition, work continues to quantify the increase in efficiency gained from the different inspection protocols.

\section{Further Work}

The inspection protocols developed for the experimental phase of the research were limited by the available technology at the remanufacturing facility. Investment in new nondestructive testing methods and technologies would allow further experimentation to investigate whether the benefits of further inspection using these methods at the Receive Core stage of remanufacturing would result in decreased processing times further through the process.

\section{References}

[1] Lund, R.T. (1984), "Remanufacturing: the experience of the USA and implications for the developing countries", World Bank Technical Paper No. 3.

[2] Guide, V.D.R. (2000.) Production planning and control for remanufacturing: industry practice and research needs. Journal of Operations Management 18, 467-483.

[3] Ijomah, W, (2002) "A model-based definition of the generic remanufacturing business process", PhD Dissertation, The University of Plymouth, UK

[4] Errington, M. (2009) "Business Processes and Strategic Framework for Inspection in Remanufacturing" PhD Dissertation, The University of Exeter, UK

[5] Östlin, J., Sundin, E., Björkman, M. (2008) "Importance of closed-loop supply chain relationships for product remanufacturing." International Journal of Production Economics $115,336-348$.

[6] Xanthopoulos, A. and Iakovou, E. (2009) "On the optimal design of the disassembly and recovery processes." Waste Management 29, 1702-1711.

[7] Teunter, R.H. and Flapper, S.D.P. (2010) Optimal core acquisition and remanufacturing policies under uncertain core quality fractions, European Journal of Operational Research, doi: 10.1016/j.ejor. 2010.06.015

[8] Lee HB, Cho NW, Hong YS. "A hierarchical end-of-life decision model for determining the economic levels of remanufacturing and disassembly under environmental regulations." Journal of Cleaner Production (2010), doi:10.1016/j.jclepro.2010.04.010 